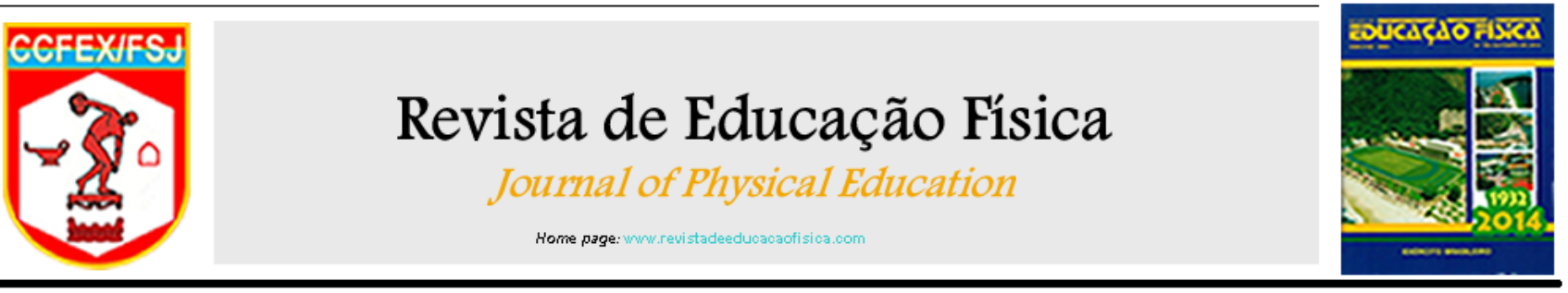

Resumo

\title{
Variabilidade na percepção subjetiva do estresse e recuperação dos jogadores da seleção brasileira de futebol na temporada 2015
}

Ivo Soares Xavier Bsci, Ângela Nogueira Neves PhD

Introdução: Muitos estudos relacionam a percepção de estresse e recuperação, buscando melhorar os programas de treinamento, e otimizar a recuperação. Porém, os estudos tem sido pouco conclusivos, e cada vez mais existe a preocupação com o desempenho dos atletas, bem como com os fatores geradores de estresse e seu equilíbrio com a recuperação.

Objetivo: 0 presente estudo traçou o perfil da percepção subjetiva do estresse e recuperação da fadiga, correlacionando com a medida de desempenho físico, $\mathrm{VO}^{2}$ máximo, em atletas da Seleção Brasileira Militar de Futebol.

Métodos: Fizeram parte do estudo 21 jogadores da Seleção Brasileira Militar de Futebol, entre 19 e 40 anos $(26,14 \pm 4,98)$, sendo o peso médio de $76,5 \mathrm{~kg}( \pm$ $7,13)$ e altura média de $1,78 \mathrm{~m}( \pm 1,80)$. Foi usado um teste indireto na coleta de dados dessa pesquisa, a saber: Versão Brasileira da Recovery Stress Questionnaire for Athletes (RESTQ-Sport), além de um teste de esforço cardiopulmonar sendo utilizado o protocolo de rampa adaptado (modulando apenas a velocidade). Os dados foram descritos com medidas de tendência central e dispersão, foi utilizado o teste de correlação de Spearman nível de confiança de 95\%. Todos os testes foram realizados no software SPSS15.

Resultados: Obtivemos o escore médio e demais estatísticas descritivas de cada um dos fatores da escala em análise, $\mathrm{VO}_{2}$ max. A correlação de Spearman indicou haver associação negativa entre $\mathrm{o} \mathrm{VO}_{2}$ max e o escore do fator de Estresse Social $(r h o=-0,52)$, e o escore do fator Fadiga $(r h o=-0,44)$. Observamos, também as diferenças entre as posições do campo.

Conclusão: 0 tempo de recuperação do atleta entre as temporadas pode ser o suficiente. 0 trabalho de condicionamento físico aeróbio deve ser privilegiado, e não apenas os fatores relacionados á prática esportiva devem ser monitorados durante a preparação atlética, e jogadores das diferentes posições devem receber treinos especificos, já que apresentaram diferentes resultados nos testes. 